\title{
ANALYTICAL METHOD DEVELOPMENT AND VALIDATION FOR THE DETERMINATION OF CAFFEINE IN GREEN COFFEE BEANS (COFFEA ARABICA L.) FROM THREE DISTRICTS OF WEST JAVA, INDONESIA BY HIGH PERFORMANCE LIQUID CHROMATOGRAPHY
}

\author{
FEBRINA AMELIA SAPUTRI, MUCHTARIDI MUCHTARIDI*
}

Department of Pharmaceutical Analysis and Medicinal Chemistry, Faculty of Pharmacy, Universitas Padjadjaran, Jl Raya Bandung Sumedang km 21 Jatinangor, West Java, Indonesia, 45363

Email: muchtaridi@unpad.ac.id

Received: 17 Jul 2018, Revised and Accepted: 04 Sep 2018

\section{ABSTRACT}

Objective: To develop and validate a simple, accurate, and precise HPLC method for the determination of caffeine in green coffee beans (Coffea arabica L.) from three districts of West Java, Indonesia.

Methods: The analytical method was conducted using Enduro C-18 (250 x $4.6 \mathrm{~mm})$ column with methanol: water (37: 63) as a mobile phase, the flow rate was $1.0 \mathrm{ml} / \mathrm{min}$, and the detector wavelength was set at $274 \mathrm{~nm}$. The selectivity, linearity, limit of detection (LOD), limit of quantification (LOQ), accuracy, precision, and system suitability testing were evaluated as the parameters of validation.

Results: The retention time of caffeine was $6.36 \mathrm{~min}$. \% RSD for precision was 0.192 . The linearity of the method was obtained using a concentration range of $1-200 \mathrm{ppm}$ with the correlation coefficient of 0.998 . The limit of detection was $9 \mathrm{ppm}$ and the limit of quantitation was 28 ppm. The accuracy was in between 90.723\%-102.853\%. Caffeine levels from Garut, Pangalengan, and Tasikmalaya were $1.454 \pm 0.004 \%, 1.574 \pm$ $0.082 \%$, and $2.280 \pm 0.004 \%$

Conclusion: The proposed HPLC method meets the acceptance criteria of validation parameters and can be applied for routine analysis.

Keywords: Analytical Method Development, Caffeine, HPLC, Validation

(C) 2018 The Authors. Published by Innovare Academic Sciences Pvt Ltd. This is an open access article under the CC BY license (http://creativecommons.org/licenses/by/4.0/) DOI: http://dx.doi.org/10.22159/ijap.2018v10i6.28551

\section{INTRODUCTION}

Caffeine (1,3,7-trimethylxanthine) is a central nervous system stimulant that prevents drowsiness, improves short-term memory, influences human circadian timing, and improves the effectiveness of particular drugs. It is an alkaloid which naturally found in the seeds, leaves or fruits of more than 63 plants species worldwide [13]. Caffeine is widely consumed by humans for many years as foods and beverages containing caffeine including coffee beverage [4-6]. The world's major source of caffeine is the coffee bean, that is the seed of the coffee plant [2].

Indonesia produced at least 748 thousand tons or $6.6 \%$ of world coffee production in 2012. In West Java, Indonesia, the production of coffee beans is mostly produced from the districts of Pangalengan, Garut, and Tasikmalaya. Every year, consumption of processed coffee products in Indonesia has grown to reach an average of $7.5 \%$. Indonesia produces robusta coffee $700 \mathrm{~kg}$ of beans/ha/year and arabica coffee of $800 \mathrm{~kg}$ beans/ha/year [7]. Robusta coffee contains caffeine almost twice (1.7$4.0 \%)$ compared to arabica coffee $(0.8-1.4 \%)[8,9]$.

The agricultural practices, processes, storages, and the agro-climatic conditions such as temperature, air/wind changes, humidity, sunlight are the factors that can create variations in the chemical composition of green coffee [1, 10]. Caffeine levels indicate the quality of coffee, and it becomes advantageous information in the selection of raw materials of foods and beverages containing caffeine. The objective of this study was to develop a simple analytical method in order to characterize and identify the amount of caffeine in coffee beans from three districts of Indonesia.

\section{MATERIALS AND METHODS}

\section{Materials}

The standard substance of caffeine was produced by Merck, USA. Methanol for HPLC was obtained from Merck, USA and water was obtained from PT. Ikapharmindo Putramas, Indonesia. Ethanol, iron (III) chloride, $1 \%$ gelatin solution, ammonia aqueous, chloroform, hydrochloric acid, Mayer reagent, Dragendorff reagent, magnesium, amyl alcohol, ether, vanillin-sulfuric acid reagent, sodium hydroxide solution, Liebermann-Buchard reagent were also purchased from Merck, USA.

\section{Apparatus}

The method development was performed with an ultraviolet-visible spectrophotometer (Analytik Jena Specord 200®) and Dionex Ultimate 3000 HPLC with an ultraviolet-visible detector (Ultimate 3000 wavelength detector).

\section{Preparation of caffeine standard solution}

Caffeine standard (50 mg) was weighed and then dissolved with water until $25 \mathrm{ml}$ in order to obtain a concentration of $2000 \mathrm{ppm}$.

\section{Determination of maximum wavelength}

Wavelength measurement performed by ultraviolet-visible spectrophotometer. Standard solution of caffeine taken as much as $50 \mu \mathrm{l}$ and then diluted with $10 \mathrm{ml}$ of water. Then maximum wavelength was analyzed by ultraviolet-visible spectrophotometer and the absorbance was read at the maximum wavelength of caffeine.

\section{Determination of molar extinction of caffeine}

Caffeine standard solution was pipetted and diluted with water up to $10 \mathrm{ml}$, in order to obtain the final concentration of $12.87 \mu \mathrm{M}$, $25.75 \mu \mathrm{M}$, and $51.50 \mu \mathrm{M}$. Then it was analyzed with a spectrophotometer and the absorbance was read at the maximum wavelength and the value of molar extinction was determined.

Optimization of the condition of analysis

Caffeine standard solution with a concentration of $0.1 \mathrm{ppm}$ was optimized using Enduro C18G column (diameter $4.6 \mathrm{~mm}$ and length $250 \mathrm{~mm}$ ) with a flow rate $1.0 \mathrm{ml} / \mathrm{min}$ and the injection volume of 20 $\mu \mathrm{l}$. Methanol and water were used as mobile phase with composition of 37:63. Detection was done using UV detector at $274 \mathrm{~nm}$. 


\section{Suitability system test}

Caffeine standard solution with a concentration of $0.1 \mathrm{ppm}$ was injected into the HPLC with the flow rate of $1 \mathrm{ml} / \mathrm{min}$ and varies of mobile phase composition. The plate number $(\mathrm{N})$, height equivalent theoretical plate (HETP), tailing factor, and the capacity factor was determined.

\section{Analytical method validation}

\section{Linearity}

Linearity was measured by varies the concentration of caffeine standards, $1,5,10,25,50,100$, and $200 \mathrm{ppm}$ were injected into the HPLC system (optimized) and repeated 3 times. A calibration curve was made by plotting the average peak area vs. concentration standard. The result of the plot was the linear curve, $y=b x+a$ with $\mathrm{R}^{2}$ as determinant linearity [11].

\section{Accuracy}

Recovery performed by the sample with the addition of a standard concentration of $80 \%, 100 \%$, and $120 \%$ caffeine then each was measured 3 times (triplo). The area under curves was entered into the regression equation of the curve calibration. Recovery $(\% \mathrm{CV})$ should be between $80-120 \%$ [12].

\section{Precision}

Standard solution of caffeine was 6 times injected and analyzed using HPLC on the same day. Precision values were expressed by the relative standard deviation $(\mathrm{RSD}) \leq 2.0 \%[12]$.

\section{Limit of quantification and limit of detection}

The limit of detection and limit of quantification were calculated statistically through regression equation of the calibration curve; the measurement value was calculated from the value of a in the regression equation $\mathrm{y}=\mathrm{ax}+\mathrm{b}[12]$.

\section{Selectivity}

Specificity or degree of deviation (selectivity) is the ability of a method to measure the analyte closely to the other components in the sample matrix. Specificity performed by optimizing to obtain the desired compound separated perfectly with other compounds, good resolution value is $>1.5$ [13].

\section{Preparation of the extract}

Plant material used was Arabica coffee (Coffea arabica L.) beans crude obtained from Garut (-7.104543899999999, 107.89615370000001), Pangalengan (-7.112753799999999, 107.60525580000001), and Tasikmalaya (-7.381957799999999, 108.32376550000004) with voucher specimen number: $19 / \mathrm{HB} / 10 / 2014$. All the plant materials were ground into powder in the different containers. 20 grams of each coffee beans powder was extracted with digestion method using $250 \mathrm{ml}$ water at a temperature of $40-50^{\circ} \mathrm{C}$ for 30 min using a magnetic stirrer $[14,15]$.

\section{Phytochemical screening}

Phytochemical screening was performed to determine phytochemical compounds contained in the extract as alkaloid, flavonoid, tannin, polyphenol, saponin, monoterpenoid, sesquiterpenoid, steroid, triterpenoid, and quinone. Phytochemical screening performed based on the Farnsworth method [16].

\section{Determination of caffeine concentration}

The sample solutions were prepared and filtered using mini pork $0.45 \mu \mathrm{l}$ then the filtered samples were injected into the HPLC system. The resulting chromatogram was then used to calculate the concentration of the caffeine in the samples.

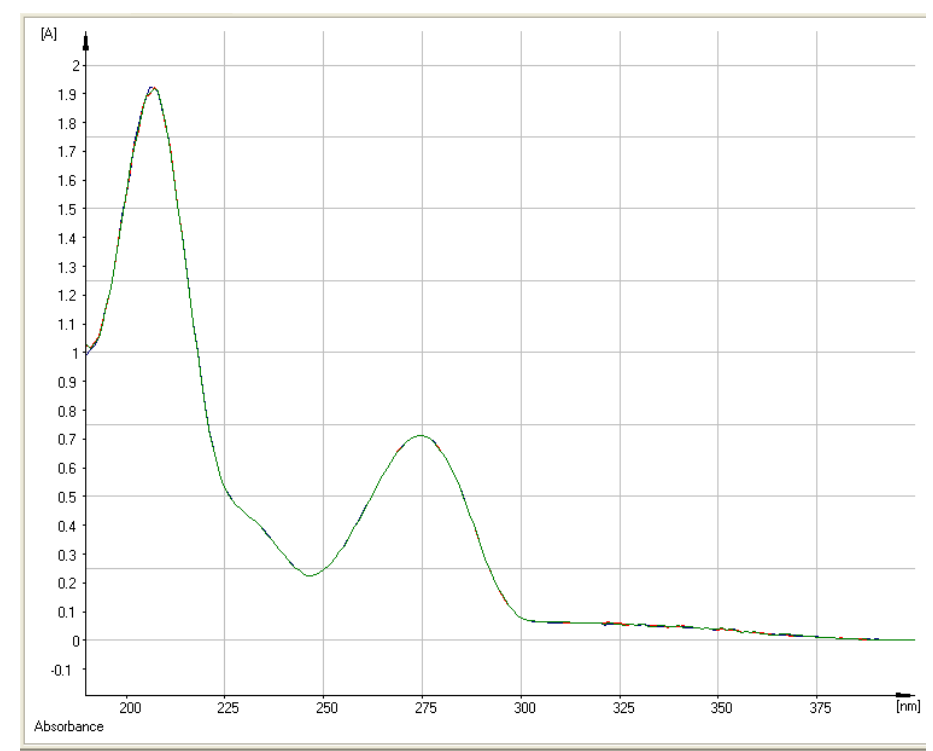

Fig. 1: Maximum wavelength of caffeine

\section{RESULTS AND DISCUSSION}

\section{Determination of wavelength maximum}

According to the British Pharmacopoeia 2013, the identification of caffeine performed at a wavelength of $275 \mathrm{~nm}$, the maximum wavelength from the optimization result was not much different, which was $274 \mathrm{~nm}$ (fig. 1) [17]. Ali et al. (2012) showed that the maximum wavelength of caffeine was $270 \mathrm{~nm}$ [18]. The differences of the maximum wavelength can be caused by different conditions between the analyses used. Because the maximum wavelength of caffeine was in the range of $200-400 \mathrm{~nm}$, the caffeine can be analyzed by using the ultraviolet detector.

\section{Determination of molar extinction of caffeine}

The results of the determination of molar extension $(\varepsilon)$ value from three different concentrations of caffeine, which were $12.87 \mu \mathrm{M}$, $25.75 \mu \mathrm{M}$, and $51.50 \mu \mathrm{M}$ can be seen in table 1 . It was $26398.049 \pm$ $5541.642 \mathrm{M}-1 \mathrm{~cm}-1$ which was greater than $10000 \mathrm{M}-1 \mathrm{~cm}-1$, so it can be concluded that caffeine can be detected using a UV detector as a chromophore. 
Table 1: Calculation of molar extinction $(\varepsilon)$ of caffeine

\begin{tabular}{llll}
\hline No & Molar concentration $(\boldsymbol{\mu M})$ & Absorbance \pm SD $(\mathbf{n}=3)$ & Molar Extinction \pm SD $(\mathbf{n}=3)$ \\
\hline 1 & 12.87 & $0.544 \pm 0.013$ & $43916.058 \pm 2112.283$ \\
2 & 25.75 & $0.275 \pm 0.004$ & $10839.952 \pm 455.714$ \\
3 & 51.50 & $0.125 \pm 0.017$ & $24438.137 \pm 4200.922$ \\
Total & & & $79194.148 \pm 16624.925$ \\
$\overline{\boldsymbol{X}}$ & & & $26398.049 \pm 5541.642$ \\
\hline
\end{tabular}

\section{Optimization of the condition of analysis}

Determination of caffeine in the extract performed by reversedphase HPLC method, the column used was Enduro C-18G $(25 \mathrm{~cm} x$ $4.6 \mathrm{~mm}$ ), a flow rate of $1 \mathrm{ml} / \mathrm{min}$, the injection volume of $20 \mu \mathrm{l}$, UV detector at wavelength $274 \mathrm{~nm}$, and the mobile phase used was methanol and water. Use of octadecyl silica has several advantages including octadecyl silica capability to separate the compounds with low polarity, moderate, or high [13].
The mobile phase used was methanol and water with ratio 37:63 obtained from the results of optimization. Water and methanol as mobile phase performed because of the economic value and ease of preparation of the solution. In the previous study, this solvent was used with a different composition. Pokhrel et al. used methanol: water 40:60 and produced recovery which was greater than $97 \%$ [19]. Methanol: water 30:70 was used as a mobile phase by Camargo et al. to determine caffeine from chocolate [20].

Table 2: Results of the optimization composition of the mobile phase

\begin{tabular}{|c|c|c|c|c|c|}
\hline Composition of mobile phase (methanol: water) & Retention time (min) & $\mathbf{N}$ & HETP (L/N) & Tailing factor & $\mathbf{K}^{\prime}$ \\
\hline $30: 70$ & 9.187 & 4156.40 & 0.060 & 1.5 & 3.835 \\
\hline $33: 67$ & 7.707 & 4124.85 & 0.0606 & 1.1 & 2.987 \\
\hline $35: 65$ & 6.960 & 3364 & 0.0743 & 1.1 & 2.756 \\
\hline $37: 63$ & 6.360 & 2393.46 & 0.104 & 1.05 & 2.419 \\
\hline
\end{tabular}

\section{System suitability test}

In table 2, it can be concluded that the composition ratio of methanol: water (37:63) is the most efficient mobile phase composition because it meets all the criteria of the optimum condition of HPLC and it has the shortest retention time and capacity factor which shows that this composition of the mobile phase gives the most efficient system for the analysis of caffeine among others. In another study, caffeine levels are determined by using more methanol than water (95:5) [21]. This becomes an oddity due to caffeine is more difficult to dissolve in water thus it is possible to expect the tailings at the peak of caffeine.

\section{Analytical method validation}

\section{Linearity}

The linear regression equation was $y=0.642 x+3024$ with $R^{2}=0$, 9985 (fig. 2). Coefficient correlation value obtained was very good, because according to UNODC, 2009 the value of the coefficient should be $\geq 0.990$ [22].

\section{Precision}

\section{Accuracy}

Recovery performed by measuring the levels of caffeine in the sample with the addition of $80 \%, 100 \%$, and $120 \%$ of the standard concentration of caffeine by then each was measured 3 times. The values of recovery meet the acceptance of accuracy, which was between 90.723\%-102.853\%.

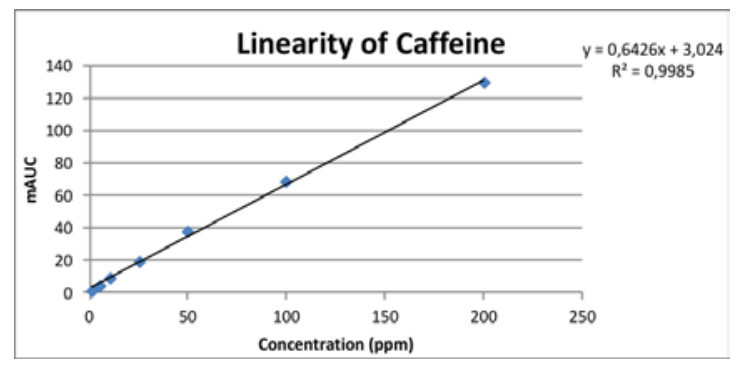

Fig. 2: Linearity of caffeine

Table 3: Precision results

\begin{tabular}{lll}
\hline ppm & AUC & Concentration \\
\hline 100 & 70.542 & 105.069 \\
100 & 70.989 & 105.766 \\
100 & 70.549 & 105.081 \\
100 & 70.513 & 105.026 \\
100 & 70.949 & 105.704 \\
100 & 70.863 & 105.570 \\
\hline & Total & 632.216 \\
& Average & 180.633 \\
& Standard deviation & 0.347 \\
\hline
\end{tabular}

Note: Number of experiments: 6

Precision values expressed by the relative standard deviation (RSD) $\leq 2.0 \%$.

Based on the results obtained in table 3, \% RSD $\leq 2.0 \%$, which was $0.192 \%$ so it can be concluded that the analytical method of caffeine meets the acceptance of precision
Limit of quantification and limits of detection: Limit of detection obtained based on the peak area was $9 \mathrm{ppm}$. Limit of quantification is defined as the smallest quantity of analyte in a sample that can be quantified and meet al. 1 the acceptance of the parameters [12]. Limit of quantification value obtained based on the peak area was $28 \mathrm{ppm}$. 


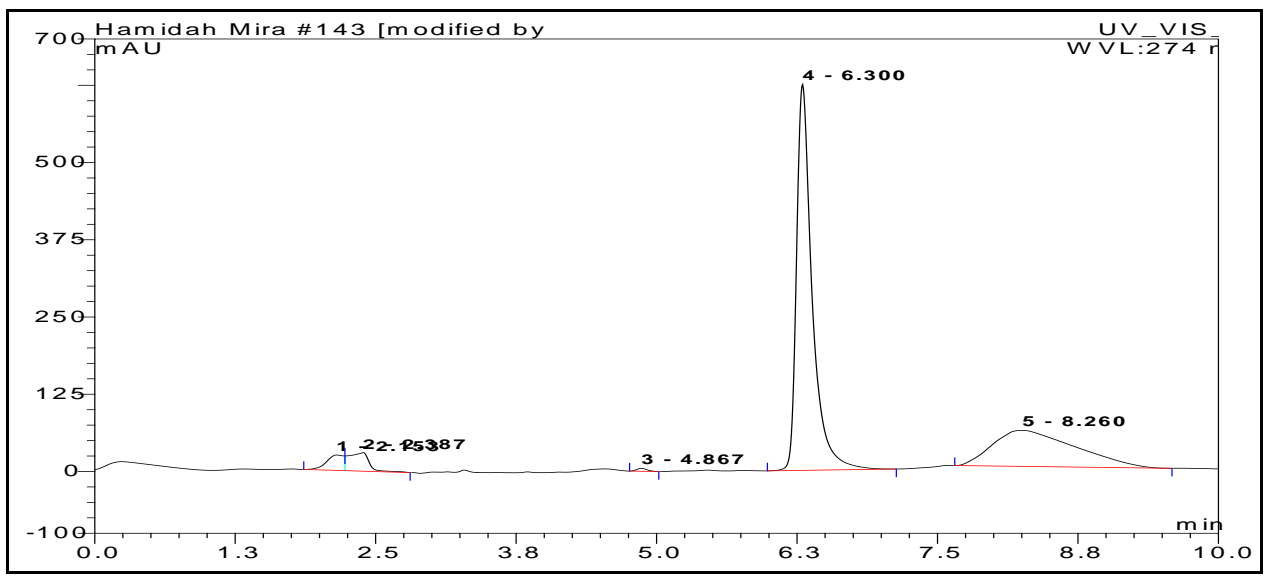

Fig. 3: Chromatogram of caffeine in the sample

\section{Selectivity}

As mention in fig. 3, can be seen the retention time of caffeine, which was $6.3 \mathrm{~min}$, apart from other peaks from the solvent with a retention time of $2.153 \mathrm{~min}$ with a resolution value 1.508 . Specificity performed by the optimization to obtain the desired compound separated perfectly with other compounds of resolution values $>1.5$ [13]. This resolution value indicates that the HPLC method can be used to analyze caffeine.

\section{Preparation of the extract}

The extracts obtained were liquid extracts with a characteristic smell of coffee and the colors were green until dark green. The volume of the liquid extract from Pangalengan was $160 \mathrm{ml}$ and the color was light green and characteristic smell of green coffee, the extract from Garut was $150 \mathrm{ml}$ and the color was pale green with a characteristic smell of green coffee, and the extract from
Tasikmalaya was $160 \mathrm{ml}$ and the color was dark green and characteristic smell of green coffee with a characteristic smell of green coffee.

\section{Phytochemical screening results}

Phytochemical screening results derived from three different regions showed similar results, which contained an alkaloid, flavonoid, tannin, polyphenol, monoterpene, sesquiterpene and triterpenoid in the extract (table 4).

\section{Determination of caffeine concentration}

Sample solution that has been filtered by using minipore $0.45 \mu \mathrm{m}$ then injected into HPLC system. It is intended that the sample injected into the HPLC has a smaller size than $0.45 \mu \mathrm{m}$ so it will not clog the column on HPLC. The area under curve was generated and then inserted into the linear regression equation and calculate the concentration of the sample used.

Table 4: Phytochemical screening results

\begin{tabular}{llll}
\hline Secondary metabolites & Garut & Pangalengan & Tasikmalaya \\
\hline Alkaloid & + & + & + \\
Flavonoid & + & + & - \\
Tannin & - & + & + \\
Polyphenol & + & - & - \\
Saponin & - & + & + \\
Monoterpene and Sesquiterpene & + & + & + \\
Triterpenoid & + & & + \\
\hline
\end{tabular}

Triterpenoid

Description: (+): Detected (-): Not detected

Table 5: Determination of caffeine in the samples from three districts West Java

\begin{tabular}{llll}
\hline Sample & Average AUC \pm SD & Concentration \pm SD (ppm) & \% Level \pm SD \\
\hline Garut & $77.794 \pm 0.249$ & $1163.561 \pm 3.724$ & $1.454 \pm 0.004$ \\
Pangalengan & $83.924 \pm 4.373$ & $1258.950 \pm 65.599$ & $1.574 \pm 0.082$ \\
Tasikmalaya & $120.244 \pm 0.243$ & $1824.160 \pm 3.686$ & $2.280 \pm 0.004$ \\
\hline
\end{tabular}

Note: Number of experiments: 3

Caffeine concentration in the samples from Garut, Pangalengan, and Tasikmalaya were $1.454 \pm 0.004 \%, 1.574 \pm 0.082 \%$, and $2.280 \pm$ $0.004 \%$, respectively (table 5). The concentrations of caffeine from three districts were different. The chemical composition of the caffeine within the same species may vary depending on the geography and season of collection [23].

\section{CONCLUSION}

The optimum condition for the analytical method of caffeine by HPLC (High-Performance Liquid Chromatography) was carried out by using Enduro C-18 column, mobile phase methanol: water (37:63) at a wavelength of $274 \mathrm{~nm}$, and the flow rate of $1 \mathrm{ml} / \mathrm{min}$. This method meets the acceptance parameters of validation. Caffeine concentration in the samples from Garut, Pangalengan, and Tasikmalaya was $1.454 \pm 0.004 \%, 1.574 \pm 0.082 \%$, and $2.280 \pm$ $0.004 \%$, respectively.

\section{AUTHORS CONTRIBUTIONS}

All the author have contributed equally 


\section{CONFLICT OF INTERESTS}

Declared none

\section{REFERENCES}

1. Weldegebreal B, Abshiro MR, Chandravanshi BS. Development of new analytical methods for the determination of caffeine content in an aqueous solution of green coffee beans. Chem Cent J 2017;11:1-9.

2. Wanyika HN, Gatebe EG, Gitu LM, Ngumba EK, Maritim CW. Determination of caffeine content of tea and instant coffee brands found in the Kenyan market. Afr J Food Sci 2010;4:353-8.

3. Burke TM, Markwald RR, McHill AW, Chinoy ED, Snider JA, Bessman SC, et al. Effects of caffeine on the human circadian clock in vivo and in vitro. Sci Transl Med 2015;7:1-9.

4. Islam MDR, Alencar MVOB, Mata AMOF, Paz MFCJ, Matos LA, Sousa JMDC, et al. Coffee: a health fuel-blot popular drinking. Int J Pharm Pharm Sci 2016;6:1-7.

5. Al Ghali RM, Al Shaibi H, Al Majed H, Haroun D. Caffeine consumption among Zayed University students in Dubai, United Arab Emirates: a cross-sectional study. Arab J Nutr Exerc 2016;1:131-41.

6. Alomar MJ. Evaluation of caffeine consumption and effect during pregnancy among women in the UAE. Int J Pharm Pharm Sci 2016;6:101-3.

7. Hartono. Coffee production of Indonesia is the biggest three in the world. [Internet]. Jakarta, Indonesia: Ministry of Industry of Indonesia; 2013. Available from: http://www.kemenperin. go.id/artikel/6611/Produksi-Kopi-Nusantara-Ketiga-TerbesarDi-Dunia. [Last accessed on 16 Jul 2018]

8. Weinberg BA, Bealer BK. The world of caffeine: the scientist and culture of the world's most popular drug. New York: Routledge; 2001.

9. Clifford M, Willson K. Coffee: botany, biochemistry, and production of beans and beverage. Croom Helm; 1985.

10. Sampaio BL, Edrada-Ebel R, Da Costa FB. Effect of the environment on the secondary metabolic profile of Tithonia diversifolia: a model for environmental metabolomics of plants. Sci Rep 2016;6:1-11.

11. Ermer J, Miller JHM. Method validation in pharmaceutical analysis: a guide to best practice. United States: John Wiley and Sons; 2005.
12. International Conference on Harmonization, Q2 Validation of analytical procedures : text and methodology international conference on harmonization of technical requirements for registration of pharmaceutical for human use, ICH Harmonized Tripartite Guideline, Canada; 2005.

13. Snyder LR, Kirkland JJ, Glajch JL. Practical HPLC method development. 2nd ed. New York, United States: WileyInterscience; 1997.

14. Atomssa T, Gholap AV. Characterization of caffeine and determination of caffeine in tea leaves using uv-visible spectrometer. Afr J Pure Appl Chem 2011;5:1-8.

15. Sharma R, Reddy VK, Prashant G, Ojha V, Kumar N. Antimicrobial and anti-adherence activity of various combinations of coffee-chicory solutions on Streptococcus mutans: an in vitro study. J Oral Maxillofac Pathol 2014;18:2016.

16. Farnsworth NR. Biological and phytochemical screening of plants. J Pharm Sci 1999;55:225-76.

17. The British Pharmacopoeia Commission, British Pharmacopoeia 2013., [internet] United Kingdom: The British Pharmacopeia Commission; 2013. Available from: http://www. uspbpep.com/bp2013/data/5420.asp. [Last accessed on $16 \mathrm{Jul}$ 2018].

18. Ali MM, Eisa M, Taha MI, Zakaria BA, Elbashir AA. Determination of caffeine in some sudanese beverages by highperformance liquid chromatography. Pakistan J Nutr 2012; 11:336-42.

19. Pokhrel P, Shrestha S, Rijal SK, Rai KP. A simple HPLC method for the determination of caffeine content in tea and coffee. J Food Sci Technol Nepal 2016;9:74-8.

20. Rojo De Camargo MC, Toledo MCF. HPLC determination of caffeine in tea, chocolate products and carbonated beverages. J Sci Food Agric 1999;79:1861-4.

21. Fajara BEP, Susanti H. HPLC determination of caffeine in the coffee beverage. IOP Conf Ser: Mater Sci Eng 2017;259:1-6.

22. United Nations Office on Drugs and Crime (UNODC), Guidance for the validation of analytical methodology and calibration of equipment used for testing of illicit drugs in seized materials and biological specimens, United Nations Publication, New York; 2009.

23. Nor Azah MA, Sam YY, Mailina J, Chua LSL. (E)-methyl cinnamate: The major component of essential oils of Alpinia malaccensis var nobilis. J Trop For Sci 2005;17:631-3. 